\title{
NEUROPSYCHOLOGY
}

\section{Neurophysiological correlates of musical creativity: The example of improvisation}

\author{
Liudmila A. Dikaya*, Irina A. Skirtach \\ Southern Federal University, Rostov-on-Don, Russia \\ *Corresponding author. E-mail: dikaya@sfedu.ru
}

\begin{abstract}
Since the turn of this century, a substantial body of research has been published on the neuroscience of creativity. Now, it is necessary to study the neurophysiological correlates in true-to-life, professionally specific situations. The aim of our empirical research was to study the neurophysiological correlates of musical improvisation, a spontaneous creative activity. The participants were 136 right-handed practicing musicians aged 19 to 36 (102 males and 34 females), divided into two groups-professionals (56 people) and amateurs ( 80 people). EEG signals were recorded in a resting state (eyes closed) and during three types of internal musical activity (perceiving, mentally reproducing, and mentally improvising) from 21 scalp electrodes according to the International 10-20 System. For statistical analysis, we used ANOVA and post hoc analysis. For the main neurophysiological correlates of musical creativity, we revealed higher values of EEG spectral power in the delta band and the dominance of long-distance functional cortical connections in the high-frequency bands. Variable neurophysiological correlates were differentiated according to emotions and the professional level of the musicians. The distinguishing EEG pattern in the professional musicians during improvisation was the predominant activation of the lefthemisphere cortical regions simultaneously with high interhemispheric integration in the high-frequency band along the "creativity axis." The revealed neurophysiological correlates of musical creativity during improvisation included basic and variable components and were characterized by a specific frequency-spatial organization of bioelectric cortical activity in the musicians.
\end{abstract}

Keywords: musical creativity, improvisation, brain cortex, EEG, spectral power, coherence, frequency band 


\section{Introduction}

In spite of the thousand-year-long history of creativity studies, creativity still remains an insufficiently studied and mysterious phenomenon. There is now an increasing interest in revealing the neural correlates of human creativity. Modern research on reorganizing physiological brain processes during the performance of creative tasks is carried out mainly on the basis of local brain blood-flow analysis by means of positron emission tomography (PET) and cerebral-cortex bioelectrical activity with the help of quantitative electroencephalography (EEG). As a rule scientists use tests with creative and control tasks in their studies. Such tests provide an opportunity to compare neurophysiological patterns of creative activity and other kinds of cognitive activity, and, as a result, they reveal clear brain correlates for exclusively creative activity. A substantial body of research has been published on the neuroscience of creativity, including some excellent review articles (for example, Abraham, 2014; Arden, Chavez, Grazioplene, \& Jung, 2010; Dietrich \& Kanso, 2010; Lustenberger, Boyle, Foulser, Mellin, \& Fröhlich, 2015; Zaidel, 2014).

The neuroscientific theories of creativity can be broadly divided into four groups based on the hypotheses that they are associated with: (1) the dominance of rightbrain-hemisphere activity, (2) high neural connectivity, (3) low cortex arousal, and (4) prefrontal and frontal brain-cortex functions (Arden, Chavez, Grazioplene, \& Jung, 2010). However, the obtained data are contradictory.

Creativity has been "placed" in the right hemisphere (Jung, Mead, Carrasco, \& Flores, 2013; Kounios \& Beeman, 2009), but there is also evidence of its left-side location (Bechtereva \& Nagornova, 2007; Dikiy, Dikaya, \& Skirtach, 2014).

Increased neural connectivity has been both proven (Mayseless \& ShamayTsoory, 2015; Razumnikova \& Yashanina, 2014) and refuted (Dikaya, Ermakov, \& Dikiy, 2012; Fink \& Benedek, 2014) in various studies as well.

According to some data, cortical activation decreases in highly creative subjects during the performance of creative tasks (Carlsson, Wendt, \& Risberg, 2000; Starchenko, Kireev, \& Medvedev, 2014) in comparison with an idle state, whereas according to other data it increases (Martindale, 1999).

Even from the point of view of prefrontal theories of creative thinking (Fink \& Benedek, 2014; Lustenberger et al., 2015), the critical role of the TPO area (collectively temporal, parietal, and occipital) is recognized as explicitly necessary for creativity (Jung et al., 2013; Kounios \& Beeman, 2014).

Thus, there is considerable heterogeneity in the results of brain research during the creative process. The contradictions in obtained data can be explained by the fact that the tasks given to the participants in such research are quite cut off from their professional work or daily life. Such tasks include, for example, composing stories by using certain words, solving anagrams, inventing in the mind an original picture or a subject made from geometrical figures (Bechtereva \& Nagornova, 2007; Kounios \& Beeman, 2014; Starchenko, Kireev, \& Medvedev, 2014; Sviderskaya, 2011).

However, a person's own inner motivation to solve a problem is the integral component in the creative process. Therefore, the study of brain activity should be carried out when research participants solve professional or daily problems related to real life. Most studies use laboratory measures of creativity, and it is unclear how these measures are related to observable behaviors in the real world. 
Musicians are a particularly relevant population to study because their intensive, long-term training may have a significant impact on neural circuits that are associated with creativity (Gibson, Folley, \& Park, 2009).

The knowledge of neurophysiological correlates and mechanisms of creative activity during the solving of real (not simulated) problems in a routine, professional life is needed by applied psychologists, managers, teachers, students, scientists, actors, artists, and many other people. The study of the psychological and psychophysiological mechanisms of the real, internally motivated creative process acquires great importance. Music composing is an example of such spontaneous creative activity. Musical creativity is defined as creating something novel in any sphere of musical art, reaching an artistic goal that reflects some important sides of reality in a unique, figurative way (Villarreal et al., 2013).

Improvisation, the process of creating something novel during a performance, plays an important role in different creative areas of life (theater, dance, and art). Improvisation is especially important in music, which reflects life in acoustical images; embodies the creativity of the composer, listener, and performer; and creates a great emotional impact.

Musical improvisation requires a musician to freely create fresh rhythmic patterns guided by the beat. This is a particularly challenging form of spontaneous creativity (Liu et al., 2012). Thus, improvisation is a kind of musical creativity. However, insufficient research has been devoted to the functional organization of the cerebral cortex during musical improvisation by musicians at different professional levels.

\section{Method}

\section{The aim and participants}

The aim of the empirical research was to study the neurophysiological correlates of musical improvisation. The research participants were 136 practicing musicians aged 19 to 36 (102 males and 34 females), divided into two groups-professionals (56 people) and amateurs ( 80 people). All participants were right-handers by birth; none were "corrected" right-handers. Handedness was assessed using the Questionnaire of Hand Preference (Annett, 1970). The musicians were pianists, guitarists, and drummers, so they used both hands equally when playing a musical instrument.

Musicians who had specialized higher education and extensive experience in creative kinds of musical activity were included in the group of professionals. Most of the professionals were multi-instrumentalists. The amateur musicians were involved in music all the time but at the amateur level; they had no special musical education, but did have extensive experience in creative kinds of musical activity. Most of the amateurs did not play more than one instrument.

In order to achieve the overall aim of the study, we established several tasks.

1. To identify basic neurophysiological correlates of musical creativity as determined by frequency-spatial bioelectrical activity of the brain cortex in musicians during improvisation as opposed to other, noncreative kinds of musical activity. 
2. To study the degree of influence of the mode of given chord sequences and the musicians' professional level on frequency-spatial bioelectrical activity of the brain cortex during improvisation in different frequency bands.

3 . To reveal varying neurophysiological correlates of musical creativity as specific frequency-spatial bioelectrical activity of the brain cortex in musicians during improvisation according to given chord sequences in various modes and in musicians at different professional levels.

\section{Experimental design}

We used the electroencephalography method (EEG). We registered the EEG results with the help of the Encephalan device in the version Elitnaya-M, which was produced by Medicom in Taganrog, Russia.

EEG signals were recorded in a resting state (eyes closed) and during three types of internal musical activity (perceiving, reproducing mentally, and improvising mentally) from 21 scalp electrodes (Fpz, Fz, Cz, Pz, Oz, Fp1, Fp2, F3, F4, F7, F8, C3, C4, T3, T4, T5, T6, P3, P4, O1, O2), set according to a monopolar scheme with ipsilateral ear referents according to the International 10-20 System.

During the first functional trial (perceiving) a sequence of major chords was presented to participants through headphones for 1 minute. Then participants were asked about the emotions evoked by this sequence. During the second trial (reproducing mentally), the participants were asked to reproduce the chord sequence mentally. During the third trial (improvising mentally), participants were invited to mentally compose an improvisation based on the previous chord sequence. After the EEG recording, participants played their improvisations on a musical instrument or wrote them down in musical notation. After a small break, the second session of trials began; during it a sequence of minor chords was presented to the participants. The following procedure was the same as in the first session.

The major and minor chord sequences were written by experts-professors of the Rostov State Conservatory named after S. V. Rachmaninoff. The participants were told that the experts would evaluate their melodies according to creativeproduct criteria (novelty, productivity, and style) as devised by Besemer \& O'Quin (1999). The winners would be offered an opportunity to record their composition in a professional recording studio. We thus created inner motivation for creating an improvisation.

Only artifactless EEG samples, 10 seconds each, were taken for analysis. The starting and ending points of each trial were indicated by the participant's pressing the mouse button. We analyzed the spectral power and coherence of EEG for each functional trial for the following frequency bands: delta $(0.50-4.00 \mathrm{~Hz})$, theta $(4.00-8.00 \mathrm{~Hz})$, alpha $(8.00-13.00 \mathrm{~Hz})$, beta $1(13.00-24.00 \mathrm{~Hz})$, and beta $2(24.00-$ $35.00 \mathrm{~Hz})$.

\section{Statistical data processing}

For statistical analysis, we used 3-way MANOVA. We analyzed the frequencyspecific effects of three factors: "Trials" (TEST): (1) resting state, (2) perceiving, (3) reproducing mentally, and (4) improvising mentally; "Musical mode" (MODE): 
(1) major and (2) minor; "Professional level" (PROF): (1) professional and (2) amateur. A comparative post hoc analysis according to the Tukey criteria was used as well. The processing was conducted with the help of STATISTICA 12.0 computer software.

\section{Results}

\section{MANOVA results}

As a result of 3-way MANOVA a number of frequency-specific effects of the factors TEST, MODE, PROF, and their interactions in functional changes of EEG spectral power and coherence were revealed. The results are shown in Tables 1-3. The main effects of TEST were more significant in the left temporal lead (T5) at the delta band $(F(1,846)=9.54, p<.001)$ in spectral power changes and between the right pre-

Table 1. The results of EEG spectral power dispersion analysis (MANOVA) of "Musical mode" (MODE), "Professional level” (PROF), and “Trials" (TEST) factors

\begin{tabular}{|c|c|c|c|c|c|c|c|c|c|c|c|c|c|c|}
\hline \multirow[t]{2}{*}{ Leads } & \multicolumn{2}{|c|}{ MODE } & \multicolumn{2}{|c|}{ PROF } & \multicolumn{2}{|c|}{ TEST } & \multicolumn{2}{|c|}{$\begin{array}{l}\text { PROF } \times \\
\text { MODE }\end{array}$} & \multicolumn{2}{|c|}{$\underset{\text { TEST }}{\text { MODE } \times}$} & \multicolumn{2}{|c|}{$\begin{array}{c}\text { PROF } \times \\
\text { TEST }\end{array}$} & \multicolumn{2}{|c|}{$\begin{array}{c}\text { PROF } \times \\
\text { MODE } \times \\
\text { TEST }\end{array}$} \\
\hline & $F$ & $p$ & $F$ & $p$ & $F$ & $p$ & $F$ & $p$ & $F$ & $p$ & $F$ & $p$ & $F$ & $p$ \\
\hline \multicolumn{15}{|c|}{ delta band $(0.5-4.0 \mathrm{~Hz})$} \\
\hline $\mathrm{F}_{3}$ & & & & & 8.04 & .00 & & & 4.83 & .05 & 5.31 & .05 & & \\
\hline $\mathrm{F}_{7}$ & & & 4.25 & .05 & 8.23 & .00 & & & & & 4.13 & .05 & & \\
\hline $\mathrm{T}_{5}$ & & & & & 9.54 & .00 & & & & & & & & \\
\hline $\mathrm{O}_{2}, \mathrm{O}_{1}, \mathrm{O}_{\mathrm{z}}$ & & & 4.86 & .05 & & & & & & & & & & \\
\hline \multicolumn{15}{|c|}{ theta band $(4.0-8.0 \mathrm{~Hz})$} \\
\hline $\mathrm{F}_{3}$ & 5.92 & .05 & 5.16 & .05 & & & 4.19 & .05 & 4.27 & .05 & 4.31 & .05 & 4.14 & .05 \\
\hline $\mathrm{F}_{4}$ & 6.85 & .01 & & & & & & & & & & & & \\
\hline $\mathrm{F}_{7}$ & 6.12 & .01 & 6.31 & .01 & & & & & 4.18 & .05 & 4.31 & .05 & & \\
\hline $\mathrm{O}_{2}, \mathrm{O}_{1}$ & & & 5.24 & .05 & & & & & & & 4.14 & .05 & & \\
\hline \multicolumn{15}{|c|}{ alpha band $(8.0-13.0 \mathrm{~Hz})$} \\
\hline $\mathrm{T}_{3}, \mathrm{~T}_{5}$ & & & 5.31 & .05 & & & & & & & 4.17 & .05 & & \\
\hline $\mathrm{T}_{4}$ & & & 6.06 & .05 & & & & & & & 4.35 & .05 & & \\
\hline \multicolumn{15}{|c|}{ beta 1 band $(13.0-24.0 \mathrm{~Hz})$} \\
\hline $\mathrm{F}_{3}$ & 5.02 & .05 & & & & & & & 4.21 & .05 & 4,32 & .05 & & \\
\hline $\mathrm{F}_{8}$ & & & & & 6.51 & .01 & & & 4.26 & .05 & & & & \\
\hline $\mathrm{O}_{2}, \mathrm{O}_{\mathrm{z}}$ & & & 5.57 & .05 & & & 4.29 & .05 & & & 4.24 & .05 & & \\
\hline \multicolumn{15}{|c|}{ beta 2 band $(24.0-35.0 \mathrm{~Hz})$} \\
\hline $\mathrm{F}_{\mathrm{p} 1}, \mathrm{~F}_{\mathrm{p} 2}, \mathrm{~F}_{\mathrm{pz}}$ & & & 5.61 & .05 & & & & & 4.19 & .05 & 4.13 & .05 & & \\
\hline $\mathrm{F}_{\mathrm{z}}, \mathrm{F}_{4}$ & & & 6.53 & .05 & & & 4.11 & .05 & 4.14 & .05 & 4.31 & .05 & & \\
\hline
\end{tabular}

Note. The table contains only significant values $(p<.05)$ 
Table 2. The results of EEG low-range coherence dispersion analysis (MANOVA) of "Musical mode" (MODE), "Professional level" (PROF), and "Trials" (TEST) factors

\begin{tabular}{|c|c|c|c|c|c|c|c|c|c|c|c|c|c|c|}
\hline \multirow[t]{2}{*}{$\begin{array}{l}\text { Pairs } \\
\text { of leads }\end{array}$} & \multicolumn{2}{|c|}{ MODE } & \multicolumn{2}{|c|}{ PROF } & \multicolumn{2}{|c|}{ TEST } & \multicolumn{2}{|c|}{$\begin{array}{l}\text { PROF } \times \\
\text { MODE }\end{array}$} & \multicolumn{2}{|c|}{$\begin{array}{c}\text { MODE } \times \\
\text { TEST }\end{array}$} & \multicolumn{2}{|c|}{$\begin{array}{l}\text { PROF } \times \\
\text { TEST }\end{array}$} & \multicolumn{2}{|c|}{$\begin{array}{c}\text { PROF } \times \\
\text { MODE } \times \\
\text { TEST }\end{array}$} \\
\hline & $F$ & $p$ & $F$ & $p$ & $F$ & $p$ & $F$ & $p$ & $F$ & $p$ & $F$ & $p$ & $F$ & $p$ \\
\hline \multicolumn{15}{|c|}{ delta band $(0.5-4.0 \mathrm{~Hz})$} \\
\hline Fp1-Fpz & 7.12 & .00 & & & & & & & 4.38 & .05 & & & & \\
\hline $\mathrm{Fpz}-\mathrm{Fp} 2$ & 6.95 & .01 & & & 5.01 & .05 & & & 4.47 & .05 & & & & \\
\hline Fp1-T4 & & & 5.92 & .05 & & & & & & & 4.58 & .05 & & \\
\hline F3-F7 & 6.85 & .01 & & & & & & & & & & & & \\
\hline $\mathrm{Fz}-\mathrm{F} 3$ & 7.34 & .00 & & & & & 4.29 & .05 & & & & & 4.18 & .05 \\
\hline F7-O1 & & & 6.67 & .01 & & & & & & & 4.64 & .05 & & \\
\hline $\mathrm{Cz}-\mathrm{C} 4$ & 4.33 & .05 & & & 7.51 & .00 & & & & & 4.72 & .05 & & \\
\hline $\mathrm{P} 3-\mathrm{Pz}$ & & & & & 7.10 & .00 & & & & & 4.20 & .05 & & \\
\hline $\mathrm{O} 1-\mathrm{O} 2$ & & & 6.35 & .01 & & & & & & & 4.14 & .05 & & \\
\hline
\end{tabular}

theta band $(4.0-8.0 \mathrm{~Hz})$

$\begin{array}{lllll}\text { Fp1-Fpz } & 5.32 & .05 & 4.13 & .05 \\ \text { F3-F7 } & 5.69 & .05 & 4.15 & .05 \\ \text { F3-T3 } & 6.87 & .01 & 4.68 & .05 \\ & & & \text { alpha band }(8.0-13.0 \mathrm{~Hz}) & \end{array}$

$\begin{array}{lllll}\text { Fp2-F8 } & 5.16 & .05 & 4.33 & .05\end{array}$

F3-F7 $\quad 4.44 \quad .05$

F3-T3 $5.16 \quad 05$

$4.13 \quad 5.16$

$\begin{array}{lllll}\text { F8-T4 } & 5.99 & .01 & 4.18 & .05\end{array}$

$\begin{array}{lllll}\text { P3-T5 } & 5.27 & .05 & 4.23 & .05\end{array}$

O2-T6 $4.32 \quad .05$

Note. The table contains only significant values $(p<.05)$.

frontal and left occipital brain regions $(\mathrm{Fp} 2-\mathrm{O} 1)$ at the beta 1 band $(F(1,486)=8.1$, $p<.001)$ in functional EEG coherence changes. MODE main effects were most prevalent in the front leads $(\mathrm{F} 3, \mathrm{~F} 4$, and $\mathrm{F} 7)$ at the theta band $(F(4,184)=5.92$, $p<.05 ; F(3,782)=6.85, p<.01$, and $F(3,46)=6.12, p<.01)$ in EEG spectral power changes. PROF main effects were revealed in changes of spectral power for all frequency bands and of EEG coherence for the low-frequency delta and high beta 1 and beta 2 bands, which covered the largest number of different areas of the brain $(p<.05)$. As can be seen from Tables $1-3$, the effects of the interaction of both TEST $\times$ MODE and TEST $\times$ PROF were expressed to the greatest extent because their influence leads to significant changes in EEG spectral power and coherence in the greatest number of different areas of the brain $(p<.05)$. 
Table 3. The results of EEG high-range coherence dispersion analysis (MANOVA) of "Musical mode" (MODE), "Professional level" (PROF), and "Trials" (TEST) factors

\begin{tabular}{|c|c|c|c|c|c|c|c|c|c|c|c|c|c|c|}
\hline \multirow[t]{2}{*}{$\begin{array}{l}\text { Pairs } \\
\text { of leads }\end{array}$} & \multicolumn{2}{|c|}{ MODE } & \multicolumn{2}{|c|}{ PROF } & \multicolumn{2}{|c|}{ TEST } & \multicolumn{2}{|c|}{$\begin{array}{l}\text { PROF } \times \\
\text { MODE }\end{array}$} & \multicolumn{2}{|c|}{$\begin{array}{c}\text { MODE } \times \\
\text { TEST }\end{array}$} & \multicolumn{2}{|c|}{$\begin{array}{c}\text { PROF } \times \\
\text { TEST }\end{array}$} & \multicolumn{2}{|c|}{$\begin{array}{c}\text { PROF } \times \\
\text { MODE } \times \\
\text { TEST }\end{array}$} \\
\hline & $F$ & $p$ & $F$ & $p$ & $F$ & $p$ & $F$ & $p$ & $F$ & $p$ & $F$ & $p$ & $F$ & $p$ \\
\hline \multicolumn{15}{|c|}{ beta 1 band $(13.0-24.0 \mathrm{~Hz})$} \\
\hline Fp1-O1 & & & 4.67 & .05 & & & & & & & & & & \\
\hline Fp1-T4 & & & 6.59 & .05 & & & 4.28 & .05 & & & 4.33 & .05 & & \\
\hline Fpz-Fp2 & 6.95 & .01 & & & & & & & 4.18 & .05 & 4.16 & .05 & & \\
\hline Fp2-P4 & & & 5.24 & .05 & & & & & & & & & & \\
\hline Fp2-O1 & & & & & 8.1 & .00 & & & 4.15 & .05 & 5.34 & .05 & 4.22 & .05 \\
\hline $\mathrm{Fp} 2-\mathrm{O} 2$ & & & 4.38 & .05 & & & & & & & & & & \\
\hline $\mathrm{Fz}-\mathrm{F} 3$ & 7.12 & .00 & & & & & 4.12 & .05 & 4.41 & .05 & & & & \\
\hline $\mathrm{F} 7-\mathrm{O} 2$ & & & 5.16 & .05 & & & & & & & 4.46 & .05 & & \\
\hline P3-T5 & 4.59 & .05 & & & & & & & 4.14 & .05 & & & & \\
\hline \multicolumn{15}{|c|}{ beta 2 band $(24.0-35.0 \mathrm{~Hz})$} \\
\hline Fp1-O1 & & & 4.28 & .05 & & & & & & & & & & \\
\hline Fp2-O1 & & & 4.49 & .05 & & & & & & & & & & \\
\hline $\mathrm{Fp} 2-\mathrm{Cz}$ & 4.64 & .05 & & & & & & & 4.19 & .05 & & & & \\
\hline F8-T6 & & & 4.77 & .05 & & & 4.17 & .05 & & & & & & \\
\hline P4-F8 & & & 5.42 & .05 & & & 4.28 & .05 & & & 4.32 & .05 & 4.12 & .05 \\
\hline $\mathrm{F} 8-\mathrm{O} 2$ & & & 5.36 & .05 & 5.27 & .03 & & & & & 4.42 & .05 & & \\
\hline $\mathrm{T} 4-\mathrm{O} 2$ & 4.76 & .05 & & & & & & & 4.16 & .05 & & & & \\
\hline $\mathrm{Oz}-\mathrm{O} 1$ & 4.73 & .05 & & & & & & & 4.11 & .05 & & & & \\
\hline
\end{tabular}

Note. The table contains only significant values $(p<.05)$.

The results of comparative analysis of the values of EEG spectral power and coherence in the musicians during different kinds of musical activity

As a result of comparative post hoc analysis we revealed the distinguishing characteristics of temporal and spatial EEG patterns in the musicians during all kinds of musical activities as compared with the resting state-characteristics such as a significantly higher level of delta rhythm power in the left frontal (F7, F3) brain cortical area $(p<.05)$.

Figure 1 presents the results of post hoc analysis of the frequency-spatial organization of cortical biopotentials in the musicians during improvisation and other kinds of musical activity.

Improvisation in comparison with other kinds of musical activity was characterized by a significantly higher level of delta power in the left posterior temporal 

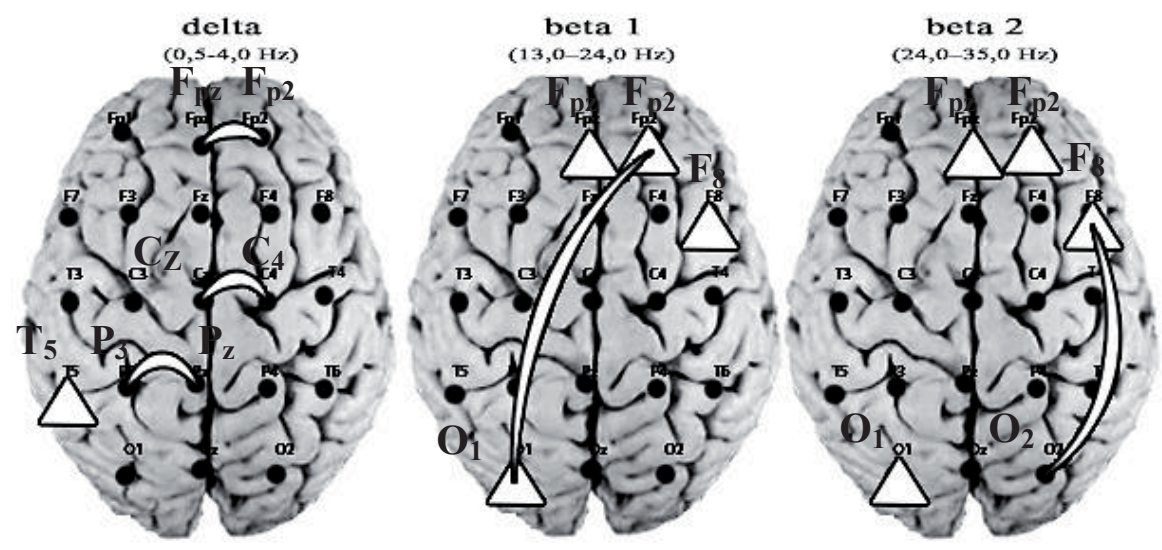

Figure 1. The results of comparative post hoc analysis of the values of EEG spectral power and coherence in the musicians during different kinds of musical activity. A triangle in the place of the corresponding lead means a higher value of spectral power; an arc means a stronger coherent connection during improvisation in comparison with other types of musical activity $(p<.05)$.

brain cortical area (T5) $(p<.05)$, where the acoustical associative regions are located; these regions are connected with the mechanism for rhythm perception and for the processing of complex musical characteristics (harmony, melody, rhythm) (Panyusheva, 2008).

Musical improvisation was also characterized by an increase of short coherences between right prefrontal (Fpz-Fp2) and central $(\mathrm{Cz}-\mathrm{C} 4)$ cortical areas and left parietal $(\mathrm{P} 3-\mathrm{Pz})$ brain areas at the delta and theta bands. A significantly higher level of spectral power at the beta 1 and beta 2 bands in right prefrontal (Fp2, Fpz), frontal (F8), and left occipital (O1) cortex areas-the "creative axis"-accompanied musical improvisation in the musicians as well $(p<.05)$. These results show that short-distance low-frequency coherence connections and the high-frequency creative axis are most relevant for the creative process in music $(p<.05)$.

The results of comparative analysis of the values of EEG spectral power and coherence in the musicians during different kinds of musical activity, as induced by major and minor chord sequences

Revealed on the basis of post hoc analysis, the distinguishing characteristics of EEG patterns in the musicians during improvisation induced by the given major and minor chord sequences in comparison with other kinds of musical activity $(p<.05)$ are shown in Figure 2.

Because each musician said that positive emotions are induced by major chord sequences and negative emotions are induced by minor chord sequences, we can reach conclusions about the positive/negative experience of emotions in musicians during improvisation according to the given major/minor chord sequences. The process of improvisation induced by the major chord sequences was accompanied by an increase of theta and beta 1 power in the left anterior regions (F3, F7) of the brain cortex and by an increase of short-distance left-hemispheric low-frequency 


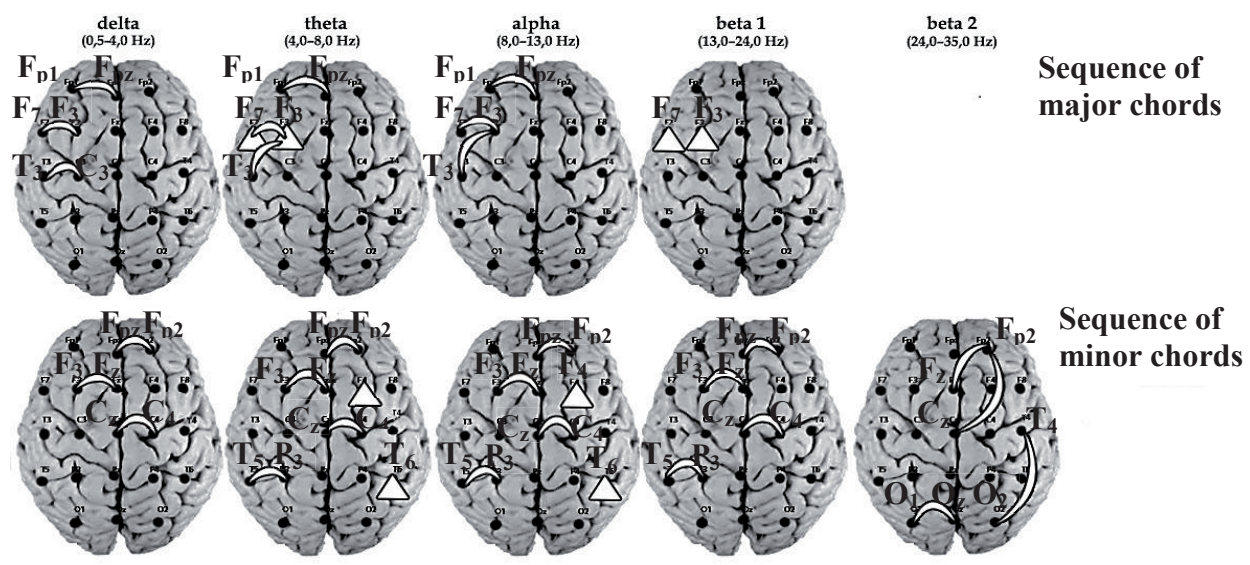

Figure 2. The results of comparative post hoc analysis of values of EEG spectral power and coherence in the musicians during different kinds of musical activity, as induced by major and minor chord sequences. A triangle in the place of the corresponding lead means a higher value of spectral power; an arc means a stronger coherent connection during improvisation in comparison with other types of musical activity $(p<.05)$.

coherence as well $(p<.05)$. The process of improvisation induced by the given minor chord sequences was accompanied by an increase of low-frequency power in the right frontal and temporal brain cortical regions, on the one hand, and by an increase of mainly right-hemispheric short-distance low-frequency coherence and long-distance high-frequency connections, on the other hand $(p<.05)$.

It is known that the anterior cortex regions reflect emotional valence and that posterior regions (especially right ones) reflect emotional activation (Elmer, Meyer, \& Jäncke, 2012). Therefore, the composition of major and minor music is reflected in the activity of right and left frontal regions accordingly. The most difficult musical improvisation is reflected in high-frequency coherent connections.

The results of comparative analysis of the values of EEG spectral power and coherence in the professional and amateur musicians during different kinds of musical activity

Revealed on the basis of comparative post hoc analysis, the cortical regions, whose functional activity during improvisation differed from functional activity during other kinds of musical activity in the professional and amateur musicians $(p<.05)$, are shown in Figure 3.

We discovered that the professional musicians had higher indexes of spectral power during improvisation than during noncreative musical activity in the delta band in the prefrontal and occipital leads in both hemispheres (Fp1, Fpz, Fp2, O1, $\mathrm{O} 2)$ and in the theta band mainly in a few areas in the left hemisphere (F3, P3, T3, O1) $(p<.05)$. Among different points of view about the theta-rhythm functional meaning, the dominant opinion is that this rhythm is a sign of emotional excitation; it is a "rhythm of tension." In the alpha band we registered higher values of spectral power in prefrontal lobes of the left hemisphere (Fp1, Fpz;) and lower val- 
ues in the temporal leads in both hemispheres (T3, T5, T4, T6) during improvisation in comparison with noncreative musical activity $(p<.05)$.

The decrease of alpha rhythm in parietal cortex areas during improvisation may be due to activation processes that appear during active mental search for an unusual melody among many ideas; this finding agrees with the data registered by Bechtereva and Nagornova (2007) when they studied the EEG spectral power during performance of the task of creating an unusual picture. A decrease of alpha rhythm in temporal cortex lobes simultaneously with an increase of delta rhythm during improvisation is probably due to the activation of inner resources in the process of a creative search. In the beta 1 band we discovered an increase of spectral power in the frontal leads of the left hemisphere (F3, F7), in posterior regions of the right hemisphere $(\mathrm{P} 4, \mathrm{O} 2)$, and in the medial frontal and occipital leads $(\mathrm{Fz}, \mathrm{Oz})$ during engagement in noncreative musical activity $(p<.05)$. In the beta 2 band we discovered an increase of spectral power in prefrontal (Fpz, Fp1), frontal (Fz, F4), and occipital $(\mathrm{O} 1, \mathrm{O} 2)$ areas of both hemispheres $(p<.05)$. The increase of the beta 1 and beta 2 bands in frontal lobes is probably connected with the search for and the evaluation of the degree of originality of a new idea. So we may say that this increase is the mechanism of self-control in the creative activity; it is the verification process, which is supposed to be quite developed in professional musicians. The increase in the beta 1 and beta 2 bands of the parietal and occipital leads may be connected with the process of creating a composition in which a musician joins several improvisation components into a single melody.

In the amateur musicians we discovered higher values of EEG spectral power during their improvisations (in comparison with their noncreative musical activity) at the delta band in the right prefrontal (Fpz, Fp2), frontal (F4), temporal (T6),
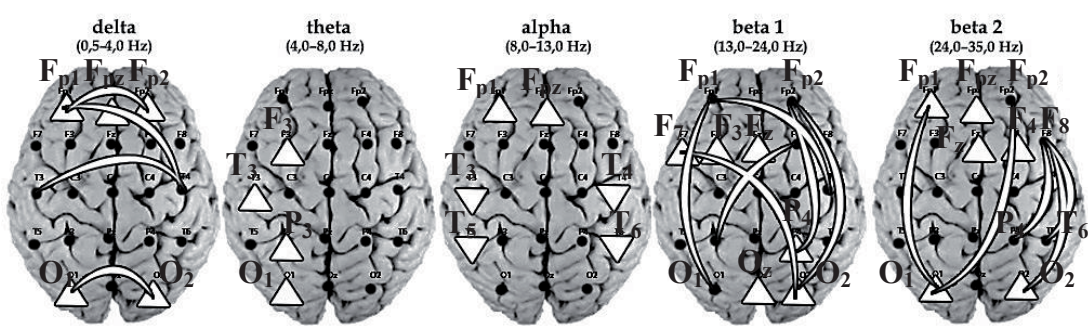

Professional musicians
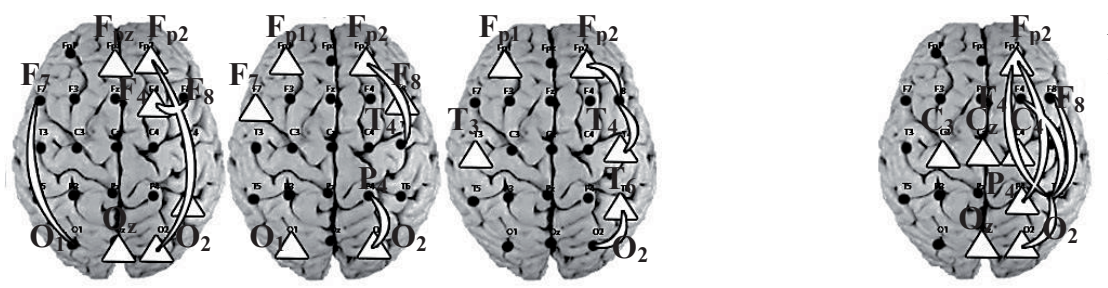

Amateur musicians

Figure 3. The results of comparative post hoc analysis of the values of EEG spectral power and coherence in the professional and amateur musicians during different kinds of musical activity. A triangle pointed up/down in the place of the corresponding lead indicates a significantly higher/lower value of spectral power; an arc indicates a significantly stronger coherent connection during improvisation in comparison with other types of musical activity $(p<.05)$. 
and occipital $\mathrm{Oz}, \mathrm{O} 2)$ leads; at the theta band in the symmetric prefrontal (Fp1, Fp2), frontal (F7, F8), and occipital $(\mathrm{O} 1, \mathrm{O} 2)$ leads; and at the alpha band in the prefrontal (Fp2, Fp1) and temporal (T3, T4, T6) leads bilaterally $(p<.05)$. The increase of alpha-rhythm values means that the degree of cortical activation decreases; thus, our data are similar to the results of the studies of other researchers who deal with the brain organization of creativity (Fink \& Benedek, 2014; Martindale, 1999). In the beta 2 band we discovered an increase of spectral power in the central area $(\mathrm{C} 3, \mathrm{C} 4, \mathrm{Cz})$, posterior regions $(\mathrm{O} 2, \mathrm{Oz}, \mathrm{P} 4)$, and right prefrontal lead $(\mathrm{Fp} 2)(p<.05)$.

During comparative post hoc analysis of the intensity and positioning of cortical functional connections during the professional musicians' improvisations in comparison with their noncreative musical activities, we discovered stronger shortdistance interhemispheric coherent connections, mainly between the homologous leads (Fp1-T4, T3-T4, O1-O2, Fp1-Fp2) at the delta band $(p<.05)$. The longdistance in- and interhemispheric coherent connections were revealed at beta 1 (Fp1-O1, Fp1-T4, Fp2-O2, Fp2-P4, F7-O2, F4-P3) and beta 2 (Fp1-O1, Fp2-O1, $\mathrm{P} 4-\mathrm{F} 8, \mathrm{~F} 8-\mathrm{O} 2, \mathrm{~F} 8-\mathrm{T} 6)$ frequency bands $(p<.05)$. Among the high-frequency interhemispheric diagonal connections discovered in the professional musicians, we have to pay attention to functional connections between the front lobes of the right and the back lobes of the left hemisphere (Fp2-O1, the creativity axis) at the beta 2 frequency band $(p<.05)$; these connections were stronger during improvisation than during other kinds of musical activity.

The amateur musicians showed stronger inhemispheric long-distance (Fp2$\mathrm{O} 2, \mathrm{~F} 7-\mathrm{O} 1)$ and short-distance (F4-F8) coherent connections at the delta band $(p<.05)$, stronger short-distance connections in the right hemisphere at the theta (Fp2-T4, O2-P4) and alpha (Fp2-F8, F8-T4, O2-T6) frequency bands $(p<.05)$, and also stronger right-hemispheric both short- $(\mathrm{O} 2-\mathrm{T} 6)$ and long-distance (Fp2$\mathrm{P} 4, \mathrm{~F} 4-\mathrm{T} 6, \mathrm{~F} 8-\mathrm{T} 6, \mathrm{Fp} 2-\mathrm{T} 6$ ) connections at the beta 2 band during improvisation than during other kinds of musical activity $(p<.05)$.

The bilateral increase in spectral power in front and back cortex areas and the functioning of strong interhemispheric connections during improvisation (in comparison with other kinds of musical activity), which were characteristic of the professional musicians, reflect the reaction of activation of inner resources for the sake of a creative search and the active process of composing a melody and evaluating its originality.

\section{Discussion}

The increase of spectral power in front and back cortical areas in the right hemisphere during improvisation (as opposed to other kinds of musical activity), which was characteristic of the amateur musicians, reflects the decrease of cortical activation and the active involvement of imagination in the creation of a melody. Our data on the spectral power changes at the alpha band in the musicians ' frontal areas during improvisation agree with the results of the studies of other researchers (Fink \& Benedek, 2014; Razumnikova \& Yashanina, 2014) who also examined the brain correlates of creative thinking. Other authors' works (Bechtereva \& Nagornova, 2007; Razumnikova \& Yashanina, 2014; Wiggins \& Bhattacharya, 2014) support 
the high value of high-frequency rhythms for the creative process, as discovered in our study.

The value of the beta 2 rhythm and its connection with the musicians' emotional reactions caused by musical stimuli has also been demonstrated in the works of Villarreal et al. (2013), who mentioned an increase of spectral power in the theta and delta bands of theater students as they were fulfilling creative tasks. We registered similar changes during musical improvisation in our study. The results of our study - the presence of strong coherent connections between right frontal and left back areas in professional musicians during improvisation - agree with the ideas about the "creative axis" (Sviderskaya, 2011).

\section{Conclusion}

This empirical research was devoted to studying the neurophysiological correlates of musical creativity in true-to-life, professionally specific situations. Relying on the results of this research, we come to the following conclusions.

1. The neurophysiological correlates of musical creativity during improvisation include basic and variable components and are characterized by a specific frequency-spatial organization of bioelectric cortical activity in musicians. The main components of neurophysiological correlates are specific for musical creativity in comparison with other kinds of musical activity. The variable components reflect the characteristics of the creative person and are differentiated according to the emotions of musicians during improvisation depending on their professional level.

2. The main neurophysiological correlates have higher values of EEG spectral power in the low-frequency delta band in hearing associative regions, which are connected with the mechanism of rhythm perception and the processing of complicated musical characteristics. They also include the dominance of long-distance in- and interhemispheric functional cortical connections in high-frequency bands.

3. Variable neurophysiological correlates that are differentiated according to emotions include the dominance of left-hemispheric activity and the strong short-distance functional connections in the left hemisphere during improvisation in the case of positive emotions and in the right hemisphere in the case of negative emotions; these emotions are induced by major and minor chord sequences.

4. The distinguishing EEG pattern in the professional musicians during improvisation was the predominant activation of the left-hemisphere cortical regions simultaneously with high interhemispheric integration in the high-frequency band along the creativity axis (between the front parts of the right hemisphere and the back parts of the left one). In the amateur musicians, improvisation caused high activation in and interaction between mainly right-hemispheric cortical regions. 
These results can be used and are used in education to develop creative and musical abilities in learners; in the psychological practice of musical psychotherapy, to correct and rehabilitate children and to develop creative abilities by means of biological feedback; in vocational guidance for musicians; and in medicine to release the creative potential of patients.

Possibilities for further investigations of the problem include studying the neural correlates of musical creativity with other musical styles and genres in musicians with different specialties and specializations and differentiated by age and sex.

\section{Acknowledgments}

This research was supported by the Ministry of Education and Science of the Russian Federation, project no. 2141.

\section{References}

Abraham, A. (2014). Creative thinking as orchestrated by semantic processing vs. cognitive control brain networks. Frontiers in Human Neuroscience, 8, 95. doi: 10.3389/ fnhum.2014.00095

Annett, M. (1970). A classification of hand preference by association analysis. British Journal of Psychology, 61(3), 303-321. doi: 10.1111/j.2044-8295.1970.tb01248.x

Arden, R., Chavez, R. S., Grazioplene, R., \& Jung, R. E. (2010). Neuroimaging creativity: A psychometric view. Behavioural Brain Research, 214(2), 143-156. doi: 10.1016/j.bbr.2010.05.015

Bechtereva, N. P., \& Nagornova, Z. V. (2007). Changes in EEG coherence during tests for nonverbal (figurative) creativity. Human Physiology, 33(5), 515-523. doi: 10.1134/S0362119707050015

Besemer, S., \& O'Quin, K. (1999). Confirming the three-factor Creative Product Analysis Matrix model in an American sample. Creativity Research Journal, 12, 287-296. doi: 10.1207/ s15326934crj1204_6

Carlsson, I., Wendt, P. E., \& Risberg, J. (2000). On the neurobiology of creativity. Differences in frontal activity between high and low creative subjects. Neuropsychologia, 38(6), 873-885. doi: 10.1016/S0028-3932(99)00128-1

Dietrich, A., \& Kanso, R. (2010). A review of EEG, ERP, and neuroimaging studies of creativity and insight. Psychological Bulletin, 136 (5), 822. doi: 10.1037/a0019749

Dikaya, L. A., Ermakov, P. N., \& Dikiy, I. S. (2012). EEG correlates of professional creative problem solving with insight. International Journal of Psychophysiology, 85(3), 379. doi: 10.1016/j. ijpsycho.2012.07.043

Dikiy, I. S., Dikaya, L. A., \& Skirtach, I.A. (2014). Interhemispheric functional organization of brain cortex in musicians during improvisation. International Journal of Psychophysiology, 94(2), 127. doi: 10.1016/j.ijpsycho.2014.08.606

Elmer, S., Meyer, M., \& Jäncke, L. (2012). The spatiotemporal characteristics of elementary audiovisual speech and music processing in musically untrained subjects. International Journal of Psychophysiology, 83(3), 259-268. doi: 10.1016/j.ijpsycho.2011.09.011

Fink, A., \& Benedek, M. (2014). EEG alpha power and creative ideation. Neuroscience \& Biobehavioral Reviews, 44, 111-123. doi: 10.1016/j.neubiorev.2012.12.002

Gibson, C., Folley, B. S., \& Park, S. (2009). Enhanced divergent thinking and creativity in musicians: A behavioral and near-infrared spectroscopy study. Brain and Cognition, 69, 162-169. doi: 10.1016/j.bandc.2008.07.009 
Jung, R. E., Mead, B. S., Carrasco, J., \& Flores, R. A. (2013). The structure of creative cognition in the human brain. Frontiers in Human Neuroscience, 7, 330. doi: 10.3389/fnhum.2013.00330

Kounios, J., \& Beeman, M. (2014). The cognitive neuroscience of insight. Annual Review of Psychology, 65(1), 71-93. doi: 10.1146/annurev-psych-010213-115154

Liu, S., Chow, H. M., Xu, Y., Erkkinen, M. G., Swett, K. E., Eagle, M. W., ... Braun, A. R. (2012). Neural correlates of lyrical improvisation: An fMRI study of freestyle rap. Scientific Reports, 2. doi: $10.1038 /$ srep00834

Lustenberger, C., Boyle, M. R., Foulser, A. A., Mellin, J. M., \& Fröhlich, F. (2015). Functional role of frontal alpha oscillations in creativity. Cortex, 67, 74-82. doi: 10.1016/j.cortex.2015.03.012

Martindale, C. (1999). Biological bases of creativity. In R. J. Sternberg (Ed.), Handbook of creativity (pp. 137-152). Cambridge, U.K.: Cambridge University Press.

Mayseless, N., \& Shamay-Tsoory, S. G. (2015). Enhancing verbal creativity: Modulating creativity by altering the balance between right and left inferior frontal gyrus with tDCS. Neuroscience, 291, 167-176. doi: 10.1016/j.neuroscience.2015.01.061

Panyusheva, T. D. (2008). Musical brain: A review of native and foreign researches. Journal of Asymmetry, 2(3), 41-54.

Razumnikova, O. M., \& Yashanina, A. A. (2014). Personality specific differences in EEG reactivity on convergent and divergent thinking. International Journal of Psychophysiology, 94(2), 160. doi: 10.1016/j.ijpsycho.2014.08.702

Starchenko, M. G., Kireev, M. V., \& Medvedev, S. V. (2014). Brain organization in creative thinking. International Journal of Psychophysiology, 94(2), 160. doi: 10.1016/j.ijpsycho.2014.08.703

Sviderskaya, N. E. (2011). Features of the spatial organization of EEG and psychophysiological characteristics of the person with the divergent and convergent thinking types. Human Physiology, 37(1), 36-44. doi: 10.1134/S0362119710061064

Villarreal, M. F., Cerquetti, D., Caruso, S., Aranguren, V.S.L., Gerschcovich, E. R., Frega, A. L., \& Leiguarda, R. C. (2013). Neural correlates of musical creativity: Differences between high and low creative subjects. PloS one, 8(9), e75427. doi: 10.1371/journal.pone.0075427

Wiggins, G. A., \& Bhattacharya, J. (2014). Mind the gap: An attempt to bridge computational and neuroscientific approaches to study creativity. Frontiers in Human Neuroscience, 8, 540. doi: $10.3389 /$ fnhum. 2014.00540

Zaidel, D. W. (2014). Creativity, brain, and art: Biological and neurological considerations. Frontiers in Human Neuroscience, 8, 389. doi: 10.3389/fnhum.2014.00389

Original manuscript received June 01, 2015 Revised manuscript accepted July 12, 2015

First published online September 30, 2015 